\title{
Seed contents of sika deer (Cervus nippon) dung and the fate of seeds in a temperate short grassland in an urban park in Japan
}

\author{
Haruna Ishikawa* \\ Laboratory of Forest Protection, Graduate School of Bioagricultural Sciences, Nagoya University, Furo-cho, Chikusa, Nagoya \\ 464-8601, Japan
}

\begin{abstract}
Many studies have suggested the positive effects of grazing by large herbivorous mammals on seed dispersal, but little is known about how herbivores could affect the fate of ingested seeds. This study examined the effects of seed ingestion by sika deer (Cervus nippon) on seed fate in a temperate grassland established in an urban park long resided by high densities of sika deer. I compared species composition and seasonal traits of seed abundance and maturity in the grassland community with those in deer fecal pellets. In total, 27 herbaceous species were observed, including the predominant Zoysia japonica. Seed phenology and production differed among the three dominant species (Z. japonica, Digitaria violascens, and Hydrocotyle maritima). Pellets contained at least 26 species of herbaceous seeds, and their abundance differed among species. Of the 26 species, 15 were observed in the vegetation at the study site. The peak of seed abundance in pellets for the dominant species appeared 1 month after the peak of inflorescence production (but most of the inflorescences were immature and susceptible to digestion) and consequently corresponded to the peak of mature inflorescence. Because sika deer are likely to ingest seeds at any maturity stage in the grassland and immature seeds are less hardened, ingested immature seeds can suffer great losses. The results suggested that the survival of germable seeds with great losses of immature seeds may be a factor determining which plant species can be successfully dispersed by herbivores.
\end{abstract}

Key words: fecal pellets, maturity of inflorescences, seed ingestion, seed phenology, sika deer grazing, vegetation

\section{INTRODUCTION}

Many plant species are dispersed by herbivorous animals (e.g., Welch 1985, Malo and Suárez 1995, Pakeman et al. 2002). Several studies have indicated that large herbivores act as potentially important seed dispersal agents (Gill and Beardall 2001, Myers et al. 2004, Cosyns and Hoffmann 2005, von Oheimb et al. 2005). After ingestion by large herbivores, seeds undergo chemical and physical attacks such as chewing, rumination, and digestion. Small, hard-coated seeds with no obvious specialized diasporas are less likely to be damaged during passage through the digestive tract of ruminants and are more likely to be dispersed in dung, whereas larger seeds are heavily damaged (Janzen 1984, Gill and Beardall 2001, Bruun and Fritzbøger 2002, Heinken et al. 2002, Pakeman et al. 2002, Myers et al. 2004, Mouissie et al. 2005). The number of germable seeds in dung varies seasonally, and this seems to reflect seed production at the grazing site (Malo and Suárez 1995). However, previous studies on seed dispersal have focused primarily on the results of germination experiments with seeds excreted by her-

\section{Open Access http://dx.doi.org/10.5141/JEFB.2011.032}

This is an Open Access article distributed under the terms of the Creative Commons Attribution Non-Commercial License (http://creativecommons. org/licenses/by-nc/3.0/) which permits unrestricted non-commercial use distribution, and reproduction in any medium, provided the original work is properly cited.
Received 25 May 2011, Accepted 30 June 2011

*Corresponding Author

E-mail: ishikawa.haruna@c.mbox.nagoya-u.ac.jp Tel: +81-52-789-4113 
bivores (e.g., Malo and Suárez 1995, Pakeman et al. 2002, Cosyns and Hoffmann 2005). Such approaches may underestimate both species and seed numbers (Couvreur et al. 2004). The dung of herbivores may also contain many seeds that cannot germinate as a result of differences in germination conditions among plant species (Grime et al. 1988, Ishikawa 2011) and/or in seed conditions such as immaturity, death, or dormancy. Grazing of immature seeds (including flower buds and flowers) or death of seeds by passing through the digestive tract may preclude the next generation. Thus, seed dispersal by herbivores can involve negative effects on plant populations and communities.

The sika deer (Cervus nippon Temminck) is a dominant large wild herbivore in Japan and consumes a range of plant materials, including bamboo leaves, grasses, tree leaves, and twigs and nuts (Miura 2005). In recent years, the population of sika deer has increased in many parts of Japan, often destroying endemic vegetation (e.g., Okuda and Nakane 1990, Shimoda et al. 1994, Akashi and Nakashizuka 1999, Maesako et al. 2007). Yamashiro and Yamashiro (2006) showed that seeds are dispersed by sika deer on a subtropical island; the deer carried many small graminoid seeds from open habitats to both open and forest habitats, and, thus, the deer probably contributed to grassland expansion. Recent elevated densities of sika deer may have a greater effect on plant communities than ever before through seed ingestion and dispersal as well as through grazing and browsing. In Japan, a Zoysiadominated community develops in the most heavily grazed places (Takatsuki 2009).

Plant species growing in short grasslands produce reproductive organs on short stems close to the leaves, and the reproductive organs are very small and intermingled with foliage. The sika deer is a grazer (Hofmann 1985), and the reproductive organs are thus likely to be ingested by the deer together with the leaves and stems at any maturity stage in the short grasslands. If sika deer continually and nonselectively graze various herbaceous plants at different developmental stages in the community, two hypotheses arise on the fate of seeds grazed by the deer: (i) sika deer dung may contain many small seeds of various herbaceous species growing at the grazing site, and (ii) immature seeds grazed by sika deer together with germable seeds may disappear during passage through the digestive tract.

The objectives of this study were to test these hypotheses by (i) comparing species composition and abundance of each species at the grazing site with those in sika deer dung and (ii) comparing the seasonal traits of production and maturity of reproductive organs (inflorescences) of dominant plant species in the community at the grazing site with those of the abundance and maturity of seeds in sika deer dung on a temperate grassland established in an urban park, Nara Park. At the same study site, Ishikawa (2010) suggested that although mature seeds of the dominant $Z$. japonica and $H$. maritima were excreted by sika deer with no reduction or enhancement of germination rate, numerous immature seeds, including flower buds and flowers, may also be ingested and are likely to suffer significant damage as a result of digestive processes. If so, seasonal traits in production and maturity of seeds in the grassland would not correspond to those of the abundance and maturity of seeds in dung.

\section{MATERIALS AND METHODS}

\section{Study site}

Nara Park (approximately 660 ha) is a large urban park, which is located in the city of Nara $\left(34^{\circ} 40^{\prime} \mathrm{N}, 135^{\circ} 50^{\prime} \mathrm{E}\right)$ in western Japan. The area has a warm-temperate climate with a mean annual rainfall of $1,338 \mathrm{~mm}$. Mean annual temperature is $14.6^{\circ} \mathrm{C}$, with an average monthly minimum of $3.8^{\circ} \mathrm{C}$ in January and a maximum of $26.6^{\circ} \mathrm{C}$ in August (1971-2000) (Japan Meteorological Agency 2011). The climax vegetation in this area is a lucidophyllous forest of Castanopsis cuspidata (Thunb.), Schottly and oak species such as Quercus glauca Thunb., Quercus myrsinifolia Blume, and Quercus sessilifolia Blume.

In Nara Park, sika deer have a home range of approximately 12 ha for females and approximately 8 ha for males and show daily activity throughout this range (Miura 1977). The deer move between open land and forest and graze in the grasslands and rest in the forests (Fukunaga and Kawamichi 1975, Fukunaga 1976). The deer have long been protected for religious reasons, and they have no natural predators. During the 1940s, the deer population in the park declined to no more than 80 individuals as a result of poaching to provide food during the war, but by 1965 it had recovered to approximately 900 , and has ranged from 1,000 to 1,300 for the last 30 years (Foundation for the Protection of Deer in Nara Park 2011). The current population level appears to be at or close to the park's carrying capacity (Torii and Tatsuzawa 2009). As a result of heavy deer impacts for many years, Nara Park has a unique ecosystem and a distinctive landscape; large open areas are covered with Zoysia-type grasslands (Takatsuki 1980), and some species that are unpalatable 
or harmful to sika deer, such as Nageia nagi (Thunb.) Kuntze and Pieris japonica (Thunb.) D. Don ex G. Don subsp. japonica, grow thickly in some places. Additionally, tree seedlings, twigs, and leaves within reach of the sika deer are browsed in the patchy forests that remain in the park, forming a so-called browse line (Crawley 1983).

This study was conducted in the Tobihino area (approximately $1.9 \mathrm{ha}$ ), which is a flat part of southeastern Nara Park (Ishikawa 2010, 2011). The deer density is particularly high (between 430 and 5,500 individuals $/ \mathrm{km}^{2}$ ) (Foundation for the Protection of Deer in Nara Park unpublished data) in the Tobihino area. The Tobihino area is covered with grasslands dominated by $Z$. japonica (Takatsuki 1980) and is one of the grazing sites in Nara Park. In the Tobihino area, sika deer depend principally on graminoids (mainly $Z$. japonica) during the growing season, but the importance of $Z$. japonica for the deer decreases greatly with the onset of the dormant season, when other forbs take its place (Takatsuki and Asahi 1977, 1978). All plant species in the grasslands have been dwarfed as a result of trampling and grazing by the high density of sika deer. Furthermore, wild boars (Susscrofa leucomystax) have been observed digging up the soil (Maesako 2002), which may be an important disturbance factor in the grassland community. In late July 2000 , the boars stripped off layers of the grassland in some places at the study site.

\section{Census and analysis of vegetation}

Censuses for plant species composition and percent cover of each species present were performed from May 2000 to December 2003. Vegetation height was assessed from May to November 2001, February to November 2002, and January to December 2003. Five permanent circular plots (each $10 \mathrm{~m}^{2}$ ) were established along a straight line for periodic vegetation censuses. There was a separation of $10 \mathrm{~m}$ between the center of one plot and the center of the next plot. In each plot, two quadrats (each $50 \mathrm{~cm} \times 50 \mathrm{~cm}$ ) were established randomly during each census. Thus, at each census, 10 quadrats were assessed for vegetation height, plant species composition, and the percentage cover of each species present in the plot.

Vegetation height, as an index of the vegetation successional stage, at each census was represented by the mean height from the 10 quadrats. Significant changes in vegetation height during the study period and in the mean vegetation height at each census were tested among months and years by means of a two-way analysis of variance (ANOVA) in the Generalized Linear Models module of SPSS ver. 11.5J for Windows (SPSS Inc., Chicago, IL, USA).

For each species, percent cover was visually evaluated using 11 ranks (from $0 \%$ to $100 \%$ at $10 \%$ intervals). Those species whose mean cover in the 10 quadrats exceeded $20 \%$ were defined as dominant species; those with 1-10\% cover were defined as species with low cover, and those with $<1 \%$ cover were defined as rare species. In the present study, the vegetation structure was represented by a combination of vegetation height and percent cover.

\section{Seed phenology and the production of inflores- cences on dominant species}

The abundance and maturity of the inflorescences of the following three dominant species were evaluated in both the vegetation and sika deer fecal pellets. Zoysia japonica is a perennial creeping grass with short leaves that produces emergent flowering stems and grows in sunny, disturbed places (Kasahara 1968, Numata and Yoshizaga 1971). Hydrocotyle maritima is a perennial creeping forb with small leaves and short stems and grows in places with high soil moisture content. It produces flowering stems shorter than its leaf stalks. Digitaria violascens is an annual tufted grass that grows in sunny places and produces flowering stems with 5-10 ears per inflorescence.

Censuses were performed from May 1999 to January 2004; Z. japonica was surveyed for 5 years starting in 1999, H. maritima in 2002 and 2003, and D. violascens in 2003. In the five fixed circular plots, the number of inflorescences was counted and their degree of maturity was visually determined for the three species. The size and number of quadrats per plot were determined to include as many inflorescences as possible for each species: two for $Z$. japonica (each $50 \mathrm{~cm} \times 50 \mathrm{~cm}$ ) and one each for $H$. maritima (each $50 \mathrm{~cm} \times 50 \mathrm{~cm}$ ) and D. violascens (each $50 \mathrm{~cm} \times 25 \mathrm{~cm}$ ). To avoid a risk of double-counting, each inflorescence was distinguished by sticking toothpicks on the soil surface close to each inflorescence after it was counted. Seed phenology was defined using four maturity stages for the inflorescences and seeds: pre-flowering (in Z. japonica and D. violascens, the heads broke through the leaf sheaths and began to grow, and in H. maritima, flower buds were formed); flowering; immature seeds (seeds and inflorescences were still green); and mature seeds (seeds and inflorescences turned brown). It was assumed that the number of inflorescences counted at each census represented the number produced during the interval between each census and the next minus the 
number consumed by sika deer.

\section{Sampling of sika deer pellets and seeds contained in the pellets}

To estimate mean fecal pellet mass, two pellets were collected from each of five pellet groups on each of six sampling occasions between May and August $(N=60)$. A pellet group was defined as a group of pellets produced by a single defecation. The pellets were dried in a convection oven $\left(85^{\circ} \mathrm{C}, 48-\mathrm{h}\right)$, weighed, and the volume of each pellet was estimated by approximating a cylinder. The mean number of pellets per pellet group was calculated from a total of 16 pellet groups in May and August 2000.

Sika deer fecal pellets were collected approximately every 2 weeks from April to July and monthly from August to November from May 1999 through November 2001. Only fresh pellets were collected, after removal of any surface material that might have contaminated them with uningested seeds. Because excretion of seeds by sika deer reaches a peak about 2 days after ingestion (Takatsuki 2006), the time lag between occurrence of seeds in these fresh pellets and seed phenology can be considered negligible. To determine the species composition and density of seeds per pellet, two (in 1999) or four pellets (in 2000 and 2001) were collected from each of five pellet groups on each sampling occasion (a total of 90 pellets in 1999 and 220 pellets each in 2000 and 2001). The pellets were air-dried and maintained at room temperature $\left(20-25^{\circ} \mathrm{C}\right)$. Each pellet was soaked in water in a Petri dish until it had absorbed enough water to soften (approximately 1-h), and was then carefully picked apart with tweezers. Seeds were separated from the pellets under a stereomicroscope (40-100× magnification) and then identified to the species level (where possible), according to specimens in a seed herbarium and specimens collected in situ. Seeds were then classified into three categories: woody plant, graminoid, or forb.

\section{RESULTS}

\section{Species composition, vegetation height, and plant community dynamics}

At least 30 plant species were recorded during the study period: 27 species were herbaceous plants belonging to 13 families (10 graminoids, 15 forbs, one grass, and one herb), one species was a bamboo, and two species were woody seedlings (Table 1). Of the 27 species, the

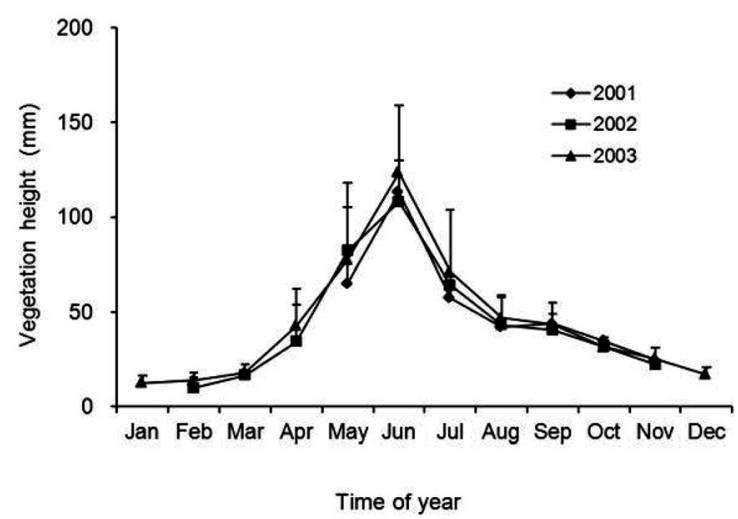

Fig. 1. Seasonal changes in the average vegetation height. Values are means \pm standard deviation ( $N=10$ on each date, except 20 September 2001, for which $N=8$ ).

dominant species were Z. japonica (Poaceae), H. maritima (Umbelliferae), D. violascens (Poaceae), and Agrostis clavata Trin. subsp. matsumurae (Hack. ex Honda) Tateoka (Poaceae). Six other herbaceous species had low cover, and the remaining 17 species were rare. The site also contained withered plants and patches of bare ground.

Vegetation height began to increase in March, reached a peak of 100-120 mm in June (the heights of the flowering stems of $Z$. japonica and A. clavata subsp. matsumurae), and then declined to a minimum of 10-15 mm in winter (Fig. 1). A significant difference was observed in vegetation height among months (two-way ANOVA; $F=$ 67.28, $\mathrm{df}=11, P<0.001)$ but not among years $(F=2.06, \mathrm{df}$ $=2, P>0.05$ ), and there was no year $\times$ month interaction $(F=0.59, \mathrm{df}=5, P>0.05)$. The 3 -year trend of low vegetation height during the winter indicates that no woody plants became established at the study site.

The total plant cover also showed a periodic trend (Fig. 2). The cover exceeded $70 \%$ from spring to autumn, except for a drop to approximately $50 \%$ in August 2000 and declined sharply in winter to less than $20 \%$ (excluding bryophytes). The cover of the four dominant species accounted for $60-80 \%$ of the plant community during the growing season. Among the dominant species, Z. japonica showed the most distinct periodic trend. The cover of $Z$. japonica was consistently high ( $>20 \%$ ) from spring to autumn throughout the study period. Digitaria violascens and A. clavata subsp. matsumurae had a typical annual cycle each year. Digitaria violascens cover peaked in autumn and exceeded $20 \%$ in 2000, 2001, and 2003. Agrostis clavata subsp. matsumurae cover increased from nearzero levels in autumn and reached a peak from spring to early summer. It exceeded $20 \%$ only in 2002 , when the cover of $\mathrm{H}$. maritima declined. Hydrocotyle maritima 


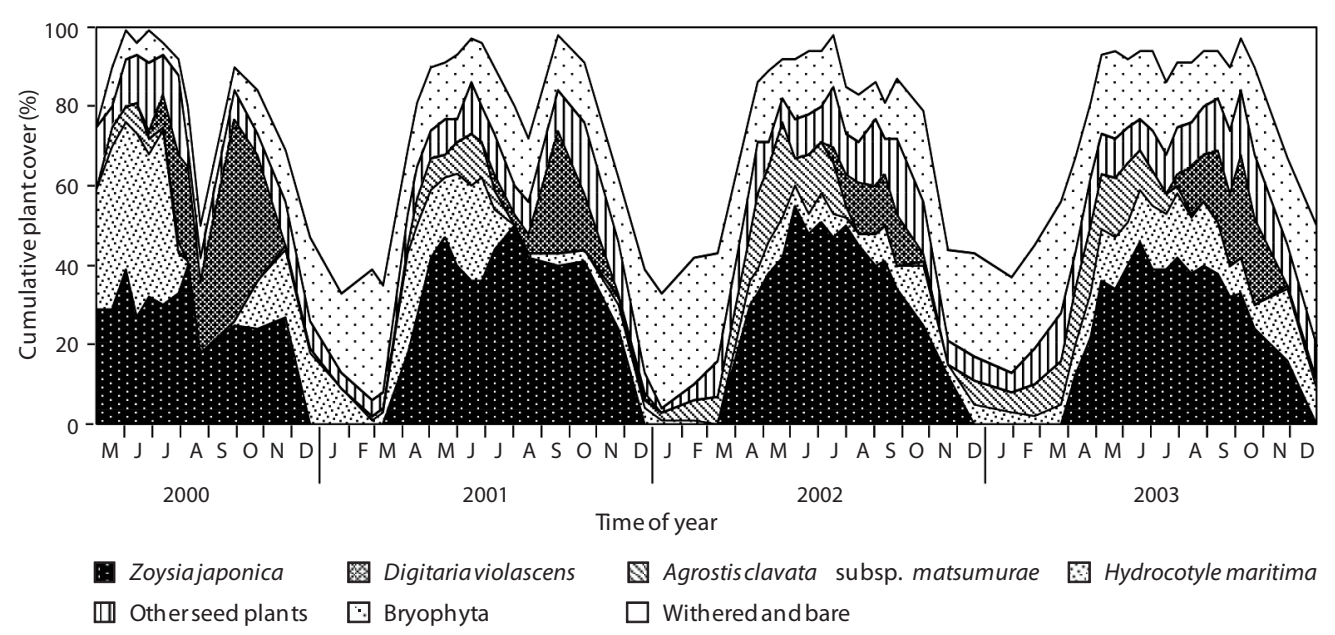

Fig. 2. Seasonal changes in the mean and cumulative plant species cover of plant species. Plant species other than the four dominant species are combined into "other seed plants" and areas with withered or no plants are included in "withered and bare."

showed a less obvious periodic trend among the 4 years, but the trends were similar in 2000 and 2001 and again in 2002 and 2003. Hydrocotyle maritima cover exceeded $20 \%$ around the first peak (from spring to summer) in 2000 and 2001 but declined to $<20 \%$ after August 2001 .

\section{Seed phenology and production of Z. japonica, $D$. violascens, and $H$. maritima inflorescences}

The maximum number of $Z$. japonica inflorescences per square meter ranged from 81.2 (in May 2000) to 249.6 (in May 2002), that of D. violascens was 3,541.3 in October 2003, and that of H. maritima was 498.4 in June 2002 and 1,370.4 in June 2003.

Because of the similarity among phenologies, only $Z$. japonica and H. maritima data for 2003 are presented in a figure (Fig. 3). Zoysia japonica inflorescences appeared in April and increased rapidly until the beginning of May then decreased gradually (Fig. 3a). The peak abundance of total and mature-seed inflorescences occurred in early May and late June, respectively. The proportion of pre-flowering inflorescences was highest in April and decreased rapidly, followed by flowering starting in late April, immature-seed inflorescences starting in early May, and mature-seed inflorescences starting in late May (Fig. 3b). The proportion of mature-seed inflorescences increased gradually from late May, and approximately $90 \%$ of inflorescences were mature in late June.

Digitaria violascens inflorescences appeared at the beginning of October and increased rapidly until late October, then decreased gradually (Fig. 3c). The peak abundance of mature-seed inflorescences occurred in early November. The proportion of pre-flowering inflorescences was highest in October, followed by flowering inflorescences from shortly after the appearance of preflowering inflorescences and immature- and matureseed inflorescences from late October onward (Fig. 3d). The proportion of mature-seed inflorescences increased gradually from late October, and approximately $70 \%$ of inflorescences were mature in mid November.

Hydrocotyle maritima inflorescences appeared in May and increased gradually until the end of June, then decreased gradually until autumn, with a peak in the number of mature-seed inflorescences in mid-July (Fig. 3e). The mature-seed inflorescences accounted for $<20 \%$ of the total from June to August. In contrast to $Z$. japonica and $D$. violascens, all inflorescence maturity stages were consistently present on each sampling date from June to September, and the relative proportion of each maturity stage was relatively constant throughout the study period (Fig. 3f). Thus, H. maritima formed flower buds and dropped seeds soon after maturity.

\section{Seeds in sika deer fecal pellets}

The mean number of pellets per defecation was $60.4 \pm$ 14.1 (mean \pm standard deviation, $N=16$; range, 33 to 99 ). The mean volume per pellet was $0.62 \pm 0.17 \mathrm{~cm}^{3}$, and the dry mass per pellet was $0.19 \pm 0.05 \mathrm{~g}(N=60)$.

In total, 530 pellets (approximately $100 \mathrm{~g}$ dry weight) from 155 fecal pellet groups were collected during the study. Overall, 2,257 seeds belonging to at least 26 species (11 graminoids and 15 forbs) from 15 families were extracted from the pellets (Table 1 ). Of the 26 species, 
Table 1. Herbaceous plant species growing in the plant community at the study site from May 2000 to December 2003, and the maximum number of seeds per sika deer fecal pellet and the total number of seeds contained in the pellets (530 pellets from May to November 1999 and from April to November in 2000 and 2001) collected in the Tobihino area of Nara Park

\begin{tabular}{|c|c|c|c|c|}
\hline Family name & Species name & Life form & Maximum & Total \\
\hline \multicolumn{5}{|c|}{$<$ Species growing in the plant community at the study site $>$} \\
\hline \multicolumn{5}{|l|}{ Dominant species } \\
\hline Poaceae & Digitaria violascens Link & Graminoid & 5 & 108 \\
\hline Poaceae & Zoysia japonica Steud." & Graminoid & 10 & 249 \\
\hline Poaceae & Agrostis clavata Trin. subsp. matsumurae (Hack. ex Honda) Tateoka & Graminoid & 5 & 54 \\
\hline Umbelliferae & Hydrocotyle maritima Honda* & Forb & 16 & 645 \\
\hline Bryophyta & Unknown & - & - & - \\
\hline \multicolumn{5}{|l|}{ Species with low cover } \\
\hline Poaceae & Poa аппиа $\mathrm{L}$. & Graminoid & 5 & 111 \\
\hline Poaceae & Paspalum thunbergii Kunth ex Steud. & Graminoid & - & - \\
\hline Poaceae & Pleioblastus sp. & & - & - \\
\hline Cyperaceae & Fimbristylis dichotoma (L.) Vahl var. tentsuki T. Koyama* & Graminoid & 6 & 41 \\
\hline Cyperaceae & Cyperus brevifolius (Rottb.) Hassk. var. leiolepis (Franch. et Sav.) T. Koyama* & Graminoid & 11 & 126 \\
\hline Caryophyllaceae & Sagina japonica (Sw.) Ohwi & Forb & 22 & 597 \\
\hline Asteraceae & Gnaphalium japonicum Thunb. & Forb & 1 & 3 \\
\hline \multicolumn{5}{|l|}{ Rare species } \\
\hline Iridaceae & Sisyrinchium rosulatum E.P. Bicknell & Forb & 1 & 1 \\
\hline Juncaceae & Juncus tenuis Willd." & Graminoid & 8 & 131 \\
\hline Poaceae & Miscanthus sinensis Andersson & Graminoid & - & - \\
\hline Poaceae & Unknown & Graminoid & - & - \\
\hline Polygonaceae & Persicaria longiseta (Bruijn) Kitag. & Forb & 6 & 21 \\
\hline Caryophyllaceae & Arenaria serpyllifolia $\mathrm{L}$. & Forb & - & - \\
\hline Caryophyllaceae & Stellaria media (L.) Vill. & Forb & 3 & 59 \\
\hline Caryophyllaceae & Stellaria uliginosa Murray var. undulata (Thunb.) Fenzl & Forb & - & - \\
\hline Caryophyllaceae & Cerastium glomeratum Thuill. & Forb & - & - \\
\hline Rosaceae & Unknown & Forb & - & - \\
\hline Clusiaceae & Hypericum laxum (Blume) Koidz. & Forb & 1 & 7 \\
\hline Fabaceae & Kummerowia striata (Thunb.) Schindl. & Forb & - & - \\
\hline Scrophulariaceae & Mazus miquelii Makino & Forb & - & - \\
\hline Plantaginaceae & Plantago asiatica $\mathrm{L}^{*}$ & Forb & 2 & 16 \\
\hline Asteraceae & Conyza sp. & Forb & - & - \\
\hline Monocotyledon & Unknown & & - & - \\
\hline Dicotyledon & Unknown & & - & - \\
\hline \multirow[t]{2}{*}{ Seedlings of woody plants } & Species 1 & & - & - \\
\hline & Species 2 & & - & - \\
\hline \multicolumn{5}{|c|}{$<$ Species that were not observed at the study site $>$} \\
\hline Juncaceae & Luzula capitata (Miq.) Miq. ex Kom. & Graminoid & 1 & 4 \\
\hline Poaceae & Isachne nipponensis Ohwi & Graminoid & 1 & 6 \\
\hline Poaceae & Cynodon dactylon (L.) Pers. & Graminoid & 1 & 2 \\
\hline Poaceae & Alopecurus aequalis Sobol. var. amurensis (Kom.) Ohwi & Graminoid & 1 & 2 \\
\hline Polygonaceae & Persicaria lapathifolia (L.) Delarbre & Forb & 3 & 9 \\
\hline Polygonaceae & Persicaria sp. & Forb & 2 & 5 \\
\hline Brassicaceae & Capsella bursa-pastoris (L.) Medik. & Forb & 1 & 1 \\
\hline Fabaceae & Trifolium repens $\mathrm{L}$. & Forb & 1 & 3 \\
\hline Violaceae & Viola verecunda A. Gray* & Forb & 1 & 3 \\
\hline Boraginaceae & Trigonotis peduncularis (Trevir.) Benth. ex Hemsl. & Forb & 1 & 1 \\
\hline Solanaceae & Physalis alkekengi $\mathrm{L}$. var. franchetii (Mast.) Makino & Forb & 1 & 2 \\
\hline Unknown & & & & 50 \\
\hline
\end{tabular}

"Species found in sika deer dung collected in the Tobihino area in June and August of 2000 and 2001 (Ishikawa 2011). 

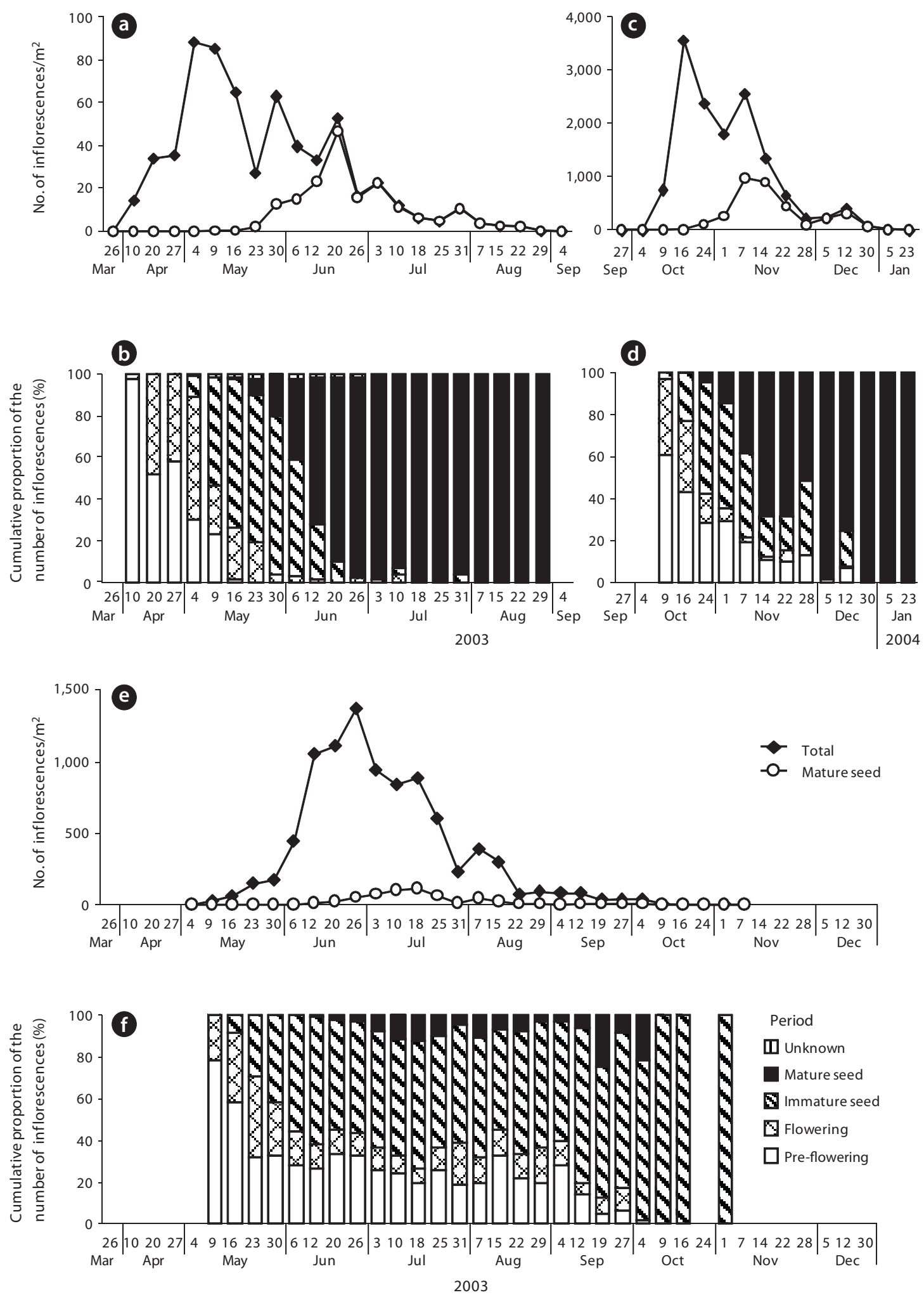

Time of year

Fig. 3. Seasonal changes in the number of inflorescences and the proportion of inflorescences at each maturity stage for (a, b) Zoysia japonica, (c, d) Digitaria violascens, and (e, f) Hydrocotyle maritima. 

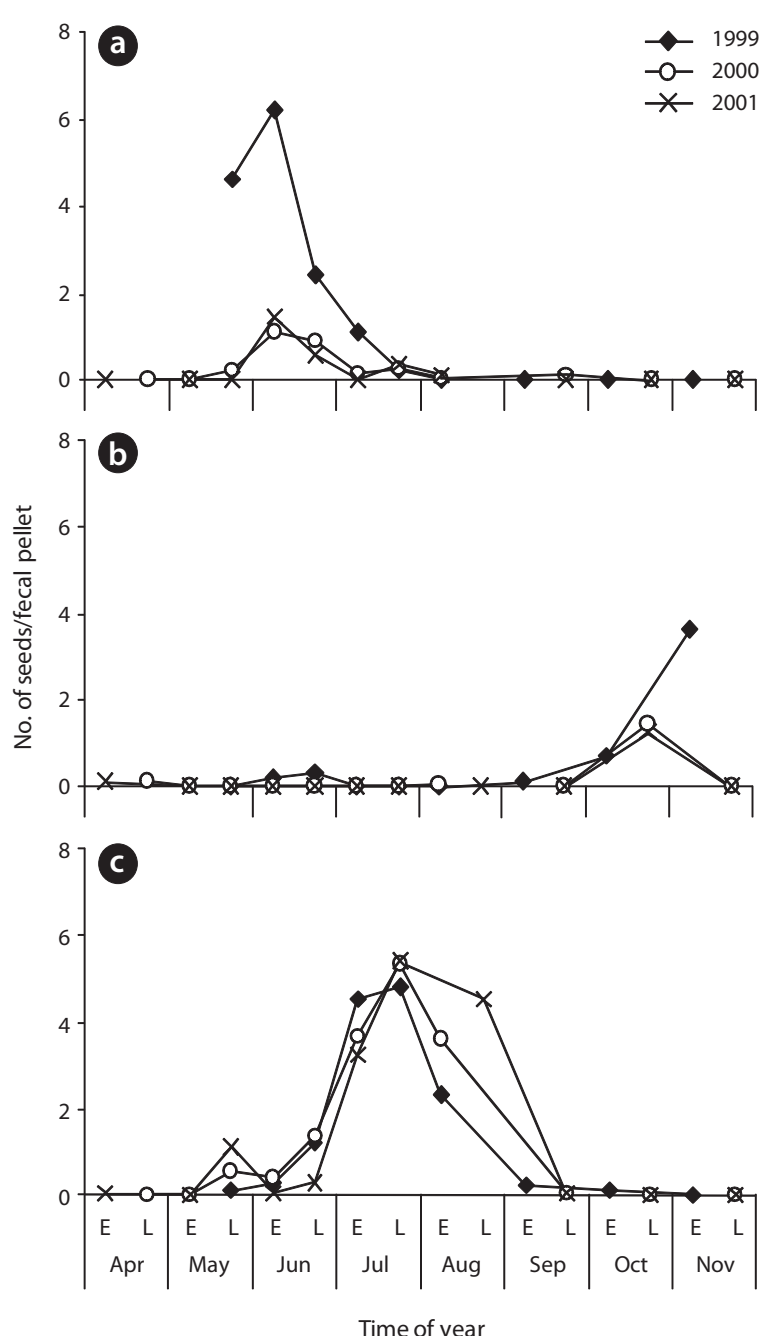

Fig. 4. Number of seeds of (a) Zoysia japonica, (b) Digitaria violascens, and (c) Hydrocotyle maritima per sika deer fecal pellet. E, early; L, late.

$58 \%$ ( 15 species) corresponded to species previously observed at this site. The total number of seeds from these 15 species accounted for $96.1 \%$ of all the seeds in pellets. The maximum number of seeds per pellet was 29 in May 2001. Of the identified species, no intact woody-plant seeds were present. The seeds of $Z$. japonica were the largest of all species collected from the pellets during the study. Many crushed Castanopsis nutshells occurred in the pellets in autumn.

The abundance of seeds extracted from the pellets differed among herbaceous species, but could be roughly classified into three groups according to the period of seed occurrence: spring-summer, midsummer, and autumn. When analyzing the species with a monthly mean of more than three seeds per pellet during the study period, Z. japonica and Sagina japonica (Sw.) Ohwi were found in pellets during the early summer, H. maritima in midsummer, and Cyperus brevifolius (Rottb.) Hassk. var. leiolepis (Franch. et Sav.) T. Koyama and D. violascens in autumn. The seed abundances of $Z$. japonica, D. violascens, and H. maritima in pellets varied seasonally (Fig. 4). The pellets contained Z. japonica seeds from May to July (Fig. 4a), D. violascens seeds from October to early November (Fig. 4b), and H. maritima seeds from May to August (Fig. 4c). The peak abundance of seeds in pellets occurred in June for Z. japonica, in late October and early November for D. violascens, and in July and August for $H$. maritima. In May, all seeds of $H$. maritima collected from pellets were immature and small (approximately 0.8 $\mathrm{mm})$.

\section{DISCUSSION}

\section{Vegetation structure and dynamics of the her- baceous plant community}

The vegetation of the Japanese archipelago, which mostly experiences a warm-humid temperate climate, is dominated by forests, and most of the existing grasslands have been established under conditions of ongoing physical disturbance or stress, such as mowing or grazing (Tagawa 1973). Under heavy intense grazing by large mammals, the vegetation of such grasslands develops as a community dominated by Z . japonica (Takatsuki 2009). For example, on Kinkazan Island in northeastern Japan, regeneration of the beech forests has been strongly suppressed by heavy sika deer browsing (Takatsuki and Ito 2009), and $Z$. japonica has rapidly invaded areas where deer density was high (Takatsuki and Gorai 1994, Takatsuki and Ito 2009). At the study site, where the sika deer population seems close to the site's carrying capacity (Torii and Tatsuzawa 2009), continual heavy grazing and trampling by the deer may be responsible for maintaining short herbaceous communities as the biotic climax stage and a dynamic equilibrium of the dominant species, such as Z. japonica, H. maritima, and D. violascens.

Obvious declines in vegetation cover of all species occurred in August 2000 due to partial stripping off of the herbaceous vegetation layers by wild boars in late July and an unusually low amount of rain in August (only 18 $\mathrm{mm}$ ). As a result of the low precipitation, the vegetation's ability to produce new biomass decreased. Although part of the area that was disturbed seriously by the boars was invaded by bryophyte species, most of the vegetation at the study site recovered after this combination of biotic and abiotic disturbances. 


\section{Seed contents of sika deer pellets}

Seeds of at least 26 herbaceous species were extracted from sika deer pellets. In the same study area, seedlings of nine of the 26 species (five graminoids and four forbs) and an additional four forb species (Duchesnea chrysantha [Zoll. et Moritzi] Miq. [Rosaceae], Oxalis corniculata L. [Oxalidaceae], Clinopodium gracile [Benth.] Kuntze [Lamiaceae], and Mazus pumilus [Burm. f.] Steenis [Scrophulariaceae]) emerged from sika deer dung in June and August 2000 and 2001 (Ishikawa 2011). Thus, viable seeds of 13 herbaceous species, including $Z$. japonica (Kitagawa 1988, Takatsuki 2006), were excreted by sika deer at the study site. Because sika deer graze on a wide variety of plants (Miura 2005) and deer densities are high in many parts of Nara Park, it is likely that many plant species other than those collected from fecal pellets in this study are excreted by the deer.

The species composition of seeds contained in fecal pellets generally reflected the vegetation at the study site; at least $58 \%$ of all species (15 of 26 species) at the study site were contained in sika deer fecal pellets, and the total number of seeds of the 15 species accounted for $96.1 \%$ of all seeds in the pellets. On a subtropical island in southern Japan, graminoid seeds dominate sika deer pellets, and more than $90 \%$ of them belonged to Cyperaceae, which are dominant in one of the foraging areas on this island (Yamashiro and Yamashiro 2006). These results reflect correlations between the abundance of the species in large herbivore dung and that in the foraging area (Couvreur et al. 2005). Although the number of seeds collected was very small (38 of 2,257 seeds), $42 \%$ of all species (11 of 26) in pellets could not be observed growing at the study site. Thus, sika deer also graze in other parts or outside of Nara Park and imported seeds from those areas to the study site.

The seed contents of pellets tended to be abundant for the dominant plant species in the community; many seeds of the dominant species $Z$. japonica, D. violascens, and $H$. maritima, were contained in pellets. However, the seed abundance in pellets did not necessarily reflect plant abundance in the community. For example, the total number of seeds of $H$. maritima and $S$. japonica contained in pellets was larger than that of the predominant $Z$. japonica. This may be attributed to differences in seed production per unit area and/or in the length of the seed production period between plant species. In this study, $H$. maritima had a larger production of inflorescences per unit area and a longer period of seed production than those of $Z$. japonica. Having more seeds may increase the probability of ingestion and increase the effectiveness of excretion via the digestive tract of sika deer at this site. Although S. japonica was not a dominant species, the maximum number of seeds per pellet was largest of all plant species. Seeds of $S$. japonica are considerably smaller $(0.4 \mathrm{~mm})$ (Nakayama et al. 2000) than those of $Z$. japonica $(2.7 \mathrm{~mm})$ (Ishikawa 2010). In previous studies, the majority of seeds excreted by sika deer (30 of 35 species) are $<2 \mathrm{~mm}$ long (Yamashiro and Yamashiro 2006) and the germable seeds dispersed by white-tailed deer (81\% of the germinations) are $<1 \mathrm{~mm}$ long (Myers et al. 2004). Having smaller seeds may increase the probability of survival during passage through the digestive tract.

\section{Comparison between seed phenology and seeds in pellets}

In Nara Park, Z. japonica heads from April to May and the seeds mature from May to June (Kitagawa 1988), and this phenology agrees with that of the present study. Other species also showed particular seasonal patterns of seed production; $D$. violascens headed from early October to early December and the seeds matured from late October, whereas $H$. maritima produced flower buds from May to September and the seeds matured from June to October. The peak abundance of mature inflorescences occurred in late June for $Z$. japonica, in early November for D. violascens, and in July for $H$. maritima. The ripening and germination rates of mature $Z$. japonica seeds rose from early June, and those of $H$. maritima were high from late July to late August (Ishikawa 2010). In contrast to $Z$. japonica and D. violascens, $H$. maritima had all stages of inflorescence maturity, and the relative proportion of mature-seed inflorescences accounted for $<20 \%$ from June to August.

Based on the results of seed production and seed abundance in pellets for Z. japonica, D. violascens, and $H$. maritima at the study site, the peak seed abundance in pellets for a given species corresponded to the peak abundance of mature inflorescences for that species but did not correspond to the peak abundance of the total of all maturity stages of inflorescences, as most seeds were still immature at that time. Immature inflorescences (flower buds, flowers, and immature seeds) are so soft that they may be digested when passing through the digestive tract. When most $Z$. japonica inflorescences were immature in the grassland from late May to early June, more than $80 \%$ of seeds excreted by sika deer had no albumen (Ishikawa 2010). Therefore, when the seed coat develops to some extent, immature or empty seeds may 
be tolerant of ingestion and be excreted during earlier periods of seed maturity. However, even if the immature seeds were excreted, they cannot germinate because they have not yet completed their development (Ishikawa 2010). Although mature-seed inflorescences of $\mathrm{H}$. maritima were $<20 \%$ of the total inflorescence abundance in the community in July and August, more than $90 \%$ of the seeds excreted by the deer had mature albumen (Ishikawa 2010). Therefore, whereas ripened seeds may have tolerance to ingestion by sika deer, immature or empty seeds were probably crushed and digested.

Previous studies on seed dispersal by large herbivores (Malo and Suárez 1995, Pakeman et al. 2002, Cosyns and Hoffmann 2005, Couvreur et al. 2005) have not considered the loss of immature reproductive organs caused by grazing. The comparison between seed phenology in the community and seeds in sika deer pellets data in this study suggests that numerous reproductive organs may be consumed at immature stages by grazing deer, and that germable seeds excreted by the deer may be a slight part of seed production in the plant community. When fertile $Z$. japonica seeds were fed to sika deer, $38 \%$ were retrieved from dung (Takatsuki 2006). Thus, considering the destruction of young reproductive organs, the ratio of excreted seeds to ingested reproductive organs would be greatly less than $38 \%$. The present study suggests that seed dispersal by large herbivores may be accompanied by heavy consumption of young reproductive organs and that not only small seed size but also the survival of germable seeds with great losses of young reproductive organs during passage through the digestive tract may be factors determining which species can successfully be dispersed by herbivores. The ingestion of seeds by sika deer is likely to affect the relative abundance of species in the plant community and will have a primary effect on the maintenance of component plant populations in Nara Park, as well as grazing and trampling.

\section{ACKNOWLEDGMENTS}

I thank Dr. N. Hijii and all members of the Laboratory of Forest Protection, Nagoya University, and Dr. T. Yoshida of Tokyo University of Agriculture and Technology for their valuable suggestions and support.

\section{LITERATURE CITED}

Akashi N, Nakashizuka T. 1999. Effects of bark-stripping by
Sika deer (Cervus nippon) on population dynamics of a mixed forest in Japan. For Ecol Manag 113: 75-82.

Bruun HH, Fritzbøger B. 2002. The past impact of livestock husbandry on dispersal of plant seeds in the landscape of Denmark. Ambio 31: 425-431.

Cosyns E, Hoffmann M. 2005. Horse dung germinable seed content in relation to plant species abundance, diet composition and seed characteristics. Basic Appl Ecol 6: 11-24.

Couvreur M, Christiaen B, Verheyen K, Hermy M. 2004. Large herbivores as mobile links between isolated nature reserves through adhesive seed dispersal. Appl Veg Sci 7: 229-236.

Couvreur M, Cosyns E, Hermy M, Hoffmann M. 2005. Complementarity of epi- and endozoochory of plant seeds by free ranging donkeys. Ecography 28: 37-48.

Crawley MJ. 1983. Herbivory: The Dynamics of Animal-Plant Interactions. University of California Press, Berkeley.

Foundation for the Protection of Deer in Nara Park. 2011. Assessment of total population of sika deer in Nara Park, Japan. http://naradeer.com/res1.htm. Accessed 25 May 2011. (in Japanese)

Fukunaga H. 1976. Behavior of sika deer (Cervus nippon) in Nara Park (I). Daily activity and habitat use (2). In: Annual Reports on Sika Deer in Nara Park (Kasuga Kenshokai, ed). Kasuga Kenshokai, Nara, pp 63-69. (in Japanese)

Fukunaga H, Kawamichi T. 1975. Behavior of sika deer (Cervus nippon) in Nara Park (I). Habitat use and daily activity. In: Annual Reports on Sika Deer in Nara Park (Kasuga Kenshokai, ed). Kasuga Kenshokai, Nara, pp 3-13. (in Japanese)

Gill RMA, Beardall V. 2001. The impact of deer on woodlands: the effects of browsing and seed dispersal on vegetation structure and composition. Forestry 74: 209-218.

Grime JP, Hodgson JG, Hunt R. 1988. Comparative Plant Ecology: A Functional Approach to Common British Species. Unwin Hyman, London.

Heinken T, Hanspach H, Raudnitschka D, Schaumann F. 2002. Dispersal of vascular plants by four species of wild mammals in a deciduous forest in NE Germany. Phytocoenologia 32: 627-643.

Hofmann RR. 1985. Digestive physiology of the deer: their morphophysiological specialization and adaptation. Bull R Soc N Z 22: 393-407.

Ishikawa H. 2010. Effects of ingestion of seeds by sika deer (Cervus nippon) and dung presence on their germination in a herbaceous community. Ecol Res 25: 591-598.

Ishikawa H. 2011. Effects of dung beetles on seedling emergence from herbaceous seeds in the dung of sika deer 
(Cervus nippon) in a temperate Japanese grassland ecosystem. Ecol Res 26: 725-734.

Janzen DH. 1984. Dispersal of small seeds by big herbivores: foliage is the fruit. Am Nat 123: 338-353.

Japan Meteorological Agency. 2011. Climate statistics in Japan. http://www.data.jma.go.jp/obd/stats/etrn/index. php. Accessed 25 May 2011. (in Japanese)

Kasahara Y. 1968. Weeds of Japan Illustrated: Seeds, Seedlings and Plants. $2^{\text {nd }}$ ed. Yokendo, Tokyo. (in Japanese)

Kitagawa N. 1988. Seed dispersal of Zoysia japonica by sika deer in the ecosystem of Nara Park. Bull Nara Bot 36: 9-12. (in Japanese)

Maesako Y. 2002. Disturbance by white-whiskered boars (Sus scrofa leucomystax) on the grassland of Tobihino, Nara Park, Nara, Central Japan. Nara Bot 24/25: 19-23. (in Japanese)

Maesako Y, Nanami S, Kanzaki M. 2007. Spatial distribution of two invasive alien species, Podocarpus nagi and Sapium sebiferum, spreading in a warm-temperate evergreen forest of the Kasugayama Forest Reserve, Japan. Veg Sci 24: 103-112.

Malo JE, Suárez F. 1995. Herbivorous mammals as seed dispersers in a Mediterranean dehesa. Oecologia 104: 246255.

Miura S. 1977. Sociological studies on Sika deer in Nara park with reference to individual distribution and behavior. In: Annual Reports on Sika Deer in Nara Park (Kasuga Kenshokai, ed). Kasuga Kenshokai, Nara, pp 3-41. (in Japanese with English summary)

Miura S. 2005. Artiodactyla. In: A Guide to the Mammals of Japan (Japan Wildlife Research Center, ed). Tokai University Press, Kanagawa, pp 107-114.

Mouissie AM, van der Veen CEJ, Veen GF(C), van Diggelen R. 2005. Ecological correlates of seed survival after ingestion by Fallow Deer. Funct Ecol 19: 284-290.

Myers JA, Vellend M, Gardescu S, Marks PL. 2004. Seed dispersal by white-tailed deer: implications for longdistance dispersal, invasion, and migration of plants in eastern North America. Oecologia 139: 35-44.

Nakayama S, Inokuchi M, Minamitani T. 2000. Seeds of Wild Plants in Japan. Tohoku University Press, Sendai. (in Japanese)

Numata M, Yoshizaga N. 1971. Weed flora of Japan: Illustrated in Colour. Zenkoku Noson Kyoiku Kyokai, Tokyo. (in Japanese)

Okuda T, Nakane K. 1990. Effects of deer browsing on the early stage of pyrogenic succession on Miyajima Island, Southeastern Japan. Ecol Res 5: 353-366.

Pakeman RJ, Digneffe G, Small JL. 2002. Ecological correlates of endozoochory by herbivores. Funct Ecol 16: 296-304. Shimoda K, Kimura K, Kanzaki M, Yoda K. 1994. The regeneration of pioneer tree species under browsing pressure of Sika deer in an evergreen oak forest. Ecol Res 9: 85-92.

Tagawa H. 1973. Ecological Lecture 11-a: Ecological Succession I. Kyoritsu Shuppan, Tokyo. (in Japanese)

Takatsuki S. 1980. The vegetation of Nara Park with reference to the grazing effects of Sika deer (Cervus nippon). In: Annual Reports on Sika Deer in Nara Park (Kasuga Kenshokai, ed). Kasuga Kenshokai, Nara, pp 113-131. (in Japanese with English summary)

Takatsuki S. 2006. Ecological History of Sika Deer. University of Tokyo Press, Tokyo. (in Japanese)

Takatsuki S. 2009. Effects of sika deer on vegetation in Japan: a review. Biol Conserv 142: 1922-1929.

Takatsuki S, Asahi M. 1977. Food habits of Sika deer in Nara Park assessed by fecal analysis (I). In: Annual Reports on Sika Deer in Nara Park (Kasuga Kenshokai, ed). Kasuga Kenshoukai, Nara, pp 129-141. (in Japanese with English summary)

Takatsuki S, Asahi M. 1978. Food habits of Sika deer in Nara Park, assessed by fecal analysis (II). In: Annual Reports on Sika Deer in Nara Park (Kasuga Kenshokai, ed). Kasuga Kenshokai, Nara, pp 25-37. (in Japanese with English summary)

Takatsuki S, Gorai T. 1994. Effects of sika deer on the regeneration of a Fagus crenata forest on Kinkazan Island, northern Japan. Ecol Res 9: 115-120.

Takatsuki S, Ito TY. 2009. Plants and plant communities on Kinkazan Island, northern Japan, in relation to sika deer herbivory. In: Sika Deer: Biology and Management of Native and Introduced Populations (McCullough DR, Takatsuki S, Kaji K, eds). Springer, Tokyo, pp 125-143.

Torii H, Tatsuzawa S. 2009. Sika deer in Nara Park: unique human-wildlife relations. In: Sika Deer: Biology and Management of Native and Introduced Populations (McCullough DR, Takatsuki S, Kaji K, eds). Springer, Tokyo, pp 347-363.

von Oheimb G, Schmidt M, Kriebitzsch WU, Ellenberg H. 2005. Dispersal of vascular plants by game in northern Germany. Part II: Red deer (Cervus elaphus). Eur J For Res 124: 55-65.

Welch D. 1985. Studies in the grazing of heather moorland in north-east Scotland. IV. Seed dispersal and plant establishment in dung. J Appl Ecol 22: 461-472.

Yamashiro A, Yamashiro T. 2006. Seed dispersal by Kerama Deer (Cervus nippon keramae) on Aka Island, the Ryukyu Archipelago, Japan. Biotropica 38: 405-413. 